\title{
AS CLÁUSULAS DE VALOR NOS CRIMES DE FURTO QUALIFICADO E A RESERVA DA LEI EM MATÉRIA PENAL: UMA REVISITAÇÃO E UM APROFUNDAMENTO *
}

\section{José De FARIa Costa**}

SUMÁRIO: I. Introdução. II. Linhas gerais da evolução legislativa. III. O dilema dos conceitos quantitativos e a tensão com a reserva de lei. IV. Conclusão.

ReSUmo: o artigo aborda criticamente a evolução, no sistema jurídico português, das cláusulas legais de valor utilizadas para a qualificação do crime de furto, chegando-se à conclusão de que o modelo atualmente em vigor implica sérias fragilidades à luz do princípio de reserva de lei em matéria penal.

Palavras-Chave: Crime de Furto Qualificado; Valor do Objeto; Definições Legais; Conceitos Quantitativos; Reserva de Lei em Matéria Penal.

AbSTRACT: the text critically analyzes the evolution, in the portuguese legal system, of the clauses of value used for the qualification of the theft crime, reaching the conclusion that the model currently adopted implies some difficulties towards the principle of legal reserve in criminal matters.

KeYwords: Grand Theft; Object Value; Legal Definitions, Quantitative Concepts; Legal Reserve in Criminal Law.

\footnotetext{
* Este estudo vai, outrossim, ser publicado em um livro de Homenagem a um caro Colega italiano: Adelmo Manna.

** Professor da Faculdade de Direito da Universidade Lusófona (Lisboa). Investigador do CEAD Centro de Estudos Avançados em Direito Francisco Suárez.
} 
O código penal português de 1982, na versão saída da reforma de 1995, considera que o valor da coisa móvel ou do animal ${ }^{1}$ subtraídos releva para efeitos de qualificação legal do crime de furto. Assim, quem subtrai coisa ou animal alheios "de valor elevado" comete um crime de furto qualificado, estando sujeito a pena de prisão até cinco anos ou com pena de multa até 600 dias. Do mesmo modo, quem subtrai coisa ou animal alheios "de valor consideravelmente elevado" arrisca uma pena de prisão de dois a oito anos ${ }^{2}$.

O teor destas duas cláusulas típicas está estabelecido no rol das definições legais previstas no artigo 202. . Assim, valor elevado é "aquele que exceder 50 unidades de conta avaliadas no momento da prática do facto". Já o valor consideravelmente elevado é "aquele que exceder 200 unidades de conta avaliadas no momento da prática do facto". Por sua vez, agora e como antes, o elemento valor é balizado por referência à unidade de conta processual (UC), a qual tem sido determinado por diplomas governamentais, ou melhor, através de um jogo de referências extra-penais que escapa ao legislador parlamentar.

Com efeito, de acordo com o artigo 22. ${ }^{\circ}$ do Decreto-Lei n. ${ }^{\circ} 34 / 2008$, de 26 de Fevereiro, na redação dada pelo Decreto-Lei n. ${ }^{0} 181 / 2008$, de 28 de Agosto, a UC "é fixada em um quarto do valor do indexante dos apoios sociais (IAS) vigente em Dezembro do ano anterior, arredondada à unidade Euro (...)”3. Para o ano em curso (2020) o IAS foi actualizado, através de

1 A autonomização destes seres vivos como objecto de protecção da norma foi recentemente introduzida pela Lei n. ${ }^{\circ} 8 / 2017$, de 3 de Março, que estabelece um estatuto jurídico dos animais. Não é nosso fito embrenharmo-nos na intrincada (e longe ainda de se encontrar um patamar mínimo de consenso) discussão da doutrina civilista sobre a verdadeira natureza jurídica do animal que (contrariamente à rigidez estática do conceito de "coisa") experiencia sentimentos de dor e de prazer, não obstante não ser dotado de racionalidade e de não ser um ente ético-socialmente comprometido. E não o é, desde logo, pela circunstância de o direito penal não ter que fazer suas, de forma absoluta, as representações normativas de outros ramos do direito, mas também por essa discussão extravasar a finalidade deste brevíssimo estudo. Não estamos com isso a desvalorizar esse importante nódulo problemático que continua a agitar a doutrina quanto à definição do sentido axiológico do animal, não obstante a tendência criadora de normas que, directa ou indirectamente, lhe conferem tutela jurídição.

2 Alínea a) do n. ${ }^{\circ} 1$ a alínea a) do $n .^{\circ} 2$ do artigo $204 .^{\circ}$, respectivamente.

3 Ali também se prevê a sua automática actualização anual com base na taxa de actualização do IAS, nos termos dos n. ${ }^{\circ} 2$ e 3 do artigo $5^{\circ}$ do Regulamento das Custas Processuais. Todavia, as sucessivas leis orçamentais dos períodos de recente crise económico-financeira implicaram a suspensão do mecanismo de atualização, tendo a legislação mais recente suspendido apenas a sua automaticidade. 
acto normativo do membro do governo responsável pela área das finanças, no valor de 438,81 euros. Todavia, por aplicação da suspensão da automaticidade do mecanismo de atualização da UC, esta segue tendo o valor de 102,00 euros, montante que se tem mantido inalterado há mais de uma década ${ }^{4}$.

Neste contexto, creio que caberá retomar um problema em outra oportunidade discutido e recolocar a questão de saber se não haverá, na técnica legislativa empregada pelo código penal português, que toca a um dos elementos do tipo presente em alguns dos crimes contra o património, uma fragilidade de legitimação constitucional, por violação do princípio de reserva de lei (parlamentar). A normação governamental (decreto-lei posteriormente densificado por regulamentação ministerial) é a sede formal-orgânica própria para definir o núcleo de desvalor de um tipo de furto qualificado?

Quando se faz esta pergunta torna-se quase impossível deixar de recordar a ideia de que as definições legais podem ser (ou na maioria das vezes são) perigosas, especialmente quando implicam, quando bolem na fundamentação ou qualificação da responsabilidade criminal'5 . Com efeito, o legislador de 1995 assumiu, neste particular, um modelo de entono anglo-saxónico no que toca à produção do statutory law. Chamou a si a intencionalidade legislativa de que certos elementos do tipo devem, à partida, ser conformados pelo espartilho textual (normativo) do próprio legislador. Mais: em um esforço de diminuição das margens de interpretação hermenêutica - mesmo que de interpretação hermenêutica teleologicamente vinculada, como deve ser toda a interpretação jurídica e muito particularmente a jurídico-penal — a lei não se satisfez em definir correctamente os comportamentos proibidos e foi além.

4 Inicialmente com base na Portaria n. ${ }^{\circ}$ 9/2008, de 3 de Janeiro.

5 Para a caracterização do fenómeno, nos seus aspectos gerais: CADoppI, Alberto, «Presentazione», IDEM (Coord.), Omnis definitio in iure periculosa? Il problema delle definizioni legali nel diritto penale, Padova: CEDAM, 1996, p. 6 s., 19 s. Por outro lado, as vicissitudes que aparecem na definição legal de conceitos surgem igualmente (mutatis mutandis) na definição legal de limiares quantitativos ( $a d$ valorem) da relevância jurídico-criminal de comportamentos. Em qualquer destes casos se trata da tipificação (em sentido amplo) de circunstâncias constitutivas da determinação do facto pelo qual o agente é chamado a responder penalmente (modus aedificandi criminis). 
Deu definições - por certo que tão-só definições legais que não absolutas descrições da realidade - de alguns elementos dos tipos ${ }^{6}$. Todavia, naturalmente, esta opção não foi uma invenção do puro engenho de um legislador caprichoso. Ela pretendeu dar respostas a determinados problemas sentidos como cruciais na compreensão do pleno sentido de desvalor dos comportamentos abrangidos pela figura do furto qualificado. O que nos impõe algum enquadramento histórico da solução, ainda que brevíssimo.

A legislação penal portuguesa de Oitocentos, referente aos crimes contra o património, assentava, no que toca a esta específica particularidade, em uma precisa ideia gradativa de escalóes, isto é, de maneira extraordinariamente simples: a um determinado montante (valor quantificado), traduzível em moeda corrente, correspondia uma certa moldura penal abstracta. Ou seja: ao aumento do montante (valor quantificado), objecto da acção, equivalia um agravamento da moldura penal abstracta (p. ex., pena maior). Em simetria, se o montante, objecto da acção, diminuísse, verificar-se-ia, de igual jeito, uma diminuição na moldura penal abstracta (p. ex., pena correccional).

No entanto, todo este mecanismo estava previamente fixado pelo legislador. E fixado, acrescente-se, de uma maneira inquebrantável. O que queria significar que, se, por uma qualquer razão, nomeadamente por motivos inflacionários, o legislador entendesse que àquele valor formal de determinado quantitativo em moeda já não devia corresponder, $v \cdot g$., uma mera "pena correccional", mas antes uma "pena maior", então, só o legislador, por acto legislativo de igual valência normativa ao que criara a norma que se queria alterar, podia modificar o preceito incriminador em causa. Este então o modelo que, no essencial, vigorou até à introdução do CP de 1982.

Fácil é de perceber que o modelo anterior ganhava uma eficácia e adquiria um sentido (um significado político-criminal) em um tipo de sociedade que se baseava na estabilidade social mas que, sobretudo, se não tinha de

6 Na perspectiva da teoria da definição do tipo legal de crime e da teoria das normas definitórias, a própria noção de definição merece ser trabalhada com cuidado. Veja-se FARIA CosTA, José, de «Le definizioni legali del dolo e della colpa quali esemplificazioni delle norme definitorie nel diritto penale», CAD OPPI, Alberto (Coord.), Omnis definitio in iure periculosa? Il problema delle definizioni legali nel diritto penale, Padova: CEDAM, 1996, p. 247 s. 
confrontar com grandes e rápidos ciclos inflacionários ou deflacionários. As intervenções legislativas, no sentido de se corrigirem as distorções introduzidas, p. ex., pela inflação - entre o valor real, efectivo, daquilo que foi objecto de um crime contra o património e a moldura penal abstracta que se tinha por mais adequada, eram poucas e espaçadas. A aceleração histórica e a motorização da produção legislativa estavam ainda longe da exasperação dos nossos dias, muito embora já se fizessem sentir.

Foi este novo quadro económico-social que fez com que se procurasse um outro modelo. Um modelo mais consentâneo às grandes mutações de valoração económica e que (agora em uma outra lógica de interpretação e aplicação do direito pena), dentro dos limites do constitucionalmente permitido, desse ao intérprete-aplicador a possibilidade de uma contínua percepção objectiva do conteúdo do objecto da acção dos crimes contra o património. Estavam achados, quer o fundamento, quer a justificação para se poder instituir o modelo legislativo que fazia do valor, não um escalão rígido, fixo e inquebrantável, em síntese, uma quantidade, mas antes uma noção cujo conteúdo, sentido e determinação se tinha que encontrar na ordem jurídico-económica. De um modelo baseado na estrita quantificação passava-se para um quadro em que a tónica era a qualificação.

Foi, precisamente, este novo modo de perceber as coisas que o legislador, com a reforma de fonds en comble do CP em 1982, introduziu entre nós. Porém, esta nova forma de compreender o elemento normativo valor real arrastou não só um enorme e injustificado movimento contrário, o que em si mesmo até se poderia ver como salutar manifestação de dissenso argumentativo ou de fundamentação, mas, por sobre tudo, uma não menor insegurança jurisprudencial.

As razões de fundo que se podem descortinar para justificar a situação anterior são susceptíveis de ser agrupadas em dois grandes núcleos: um primeiro que se prende com a normal recusa da inovação, seja tecnológica, seja comportamental, seja social, seja, enfim, legislativa; um segundo que se liga à ideia de se não ter percebido que a qualificação não tem, nem de longe nem de perto, de ser expressão de uma pura subjectivização, logo, lugar privilegiado de eventual arbítrio e indeterminação na aplicação da lei penal, e que, bem ao contrário, quando correctamente entendida, é 
também um dos caminhos seguros para se chegar, tanto quanto possível, a uma objectivização da determinação ${ }^{7}$.

\section{III}

Uma outra afirmação deve fazer-se: a determinação conceitual por quantificação é, em si mesma, aquela que, sem sombra de dúvidas, maiores garantias dá para se chegar a um patamar susceptível de, por todos, ser identificado. Mil euros são mil euros e ninguém terá dúvidas de que se uma coisa for furtada e valer mil euros, isto é, se as leis do mercado lhe atribuírem esse valor, está, então, determinado o valor que irá detonar as respectivas consequências jurídicas, nomeadamente existência ou não de crime qualificado ${ }^{8}$

Sucede, porém, que o benefício retirado deste rigor pode, em muitas circunstâncias, não ser bastante para compensar o sentimento de injustiça que se pode experienciar - não em uma perspectiva de pura e aqui intolerável subjectividade mas antes naquela que assenta na riqueza e no rigor possível da determinação intersubjectiva - quando confrontados com situações de limite. E se a "coisa" tiver um valor venal de novecentos e noventa e nove euros? Pelo puro modelo quantificador outra solução nos não resta senão aceitar que se não está perante um crime qualificado de furto.

Ora, foi precisamente este quadro que o legislador de 1982 achou por bem alterar de maneira particularmente incisiva. Modificar o modo de determinação das noções em questão e advogar uma ruptura que introduzisse conceitos - tidos tradicionalmente como de exclusiva determinação quantitativa - em que a objectiva determinação seria levada a cabo por uma tensa, contínua e ininterrupta relação hermenêutica do intérprete com as manifestações ou erupções - económicas, sociais, etc., - mais salientes da comunidade. Com o novo quadro poder-se-ia, assim, evitar, entre outras coisas, a rigidez inultrapassável do limite, criticado no

7 Neste tópico II acompanhou-se muito de perto o que escrevemos em «Definições legais», Figueiredo Dias, Jorge de (Coord.), Comentário Conimbricense do Código Penal. Parte Especial, Tomo II, Coimbra: Coimbra Editora, 1999, artigo 202. ${ }^{\circ}$, $\$ 1$ e 17-19.

8 Aceitando-se, v.g., que a qualificação se opera com um valor superior a novecentos e noventa $\mathrm{e}$ nove euros. 
parágrafo anterior, e, desse jeito, levar a cabo uma aplicação do direito penal mais adequada e mais justa.

Todavia, a plasticidade interpretativa e aplicadora que o modelo de 82 permitia necessitava - o que não aconteceu, por diversíssimas razões cujo aprofundamento crítico seria, aqui, absolutamente despropositado - que sobre ela se não tivesse criado uma caótica e inconsequente discussão. Desde logo, a utilização da palavra "valor" fez desencadear a ideia de que se estava perante um estrito e clássico elemento normativo do tipo, esquecendo-se que, não obstante a indesmentível dimensão normativizante que o elemento transportava, de modo algum ele se podia confundir com os clássicos elementos normativos (v.g., "pudor" ou, depois da revisão de 95, "acto sexual de relevo").

$\mathrm{Na}$ verdade, o "valor" que se queria determinar, nos crimes contra o património, não era uma qualquer noção concebível unicamente a partir de meras qualificações axiológicas. Antes, aquele "valor" devia ser visto como uma primeira aproximação aos quantitativos que o mercado fixava ${ }^{9}$ para tudo aquilo que tem "valor" venal. O "valor" a que se apelava não era uma pura apreensão axiológica mas, ao invés, uma realidade que se queria quantificável, muito embora sem os rigidíssimos espartilhos do modelo dos escalóes.

No entanto, a polissemia do sintagma "valor" foi, sem se dar conta disso mesmo, a razão que mais fundo devastou o quadro de referência introduzido pela lei em 1982. Mas não foi só essa flutuação a determinar o coro de vozes que apostrofavam a nova lei, se bem que, diga-se em honra da verdade, a mais qualificada jurisprudência já tivesse chegado, em princípios dos anos 90 do passado século, a uma séria e estável linha compreensiva do que fosse "valor", "valor elevado" ou "valor consideravelmente elevado". Bem vistas as coisas, na ânsia incontrolada (e, a nossos olhos, injustificada) de se encontrarem referências de determinação para o sentido do que fosse "valor elevado" ou "valor consideravelmente elevado", subjectivizou-se o elemento do tipo a patamares insustentáveis - aqui sim — perante o mais lato dos princípios da tipicidade.

9 O quadro a óleo da Vieira da Silva tem um valor de mercado, que não é um valor em si mesmo; se vale mais por ser da Vieira da Silva isso é absolutamente irrelevante para o valor de mercado, rectius, o valor de mercado incorpora obviamente o dado que advém de o quadro ser de autoria da Vieira da Silva. 
O montante de uma pequeníssima pensão furtado a um reformado, que dele dependia, passou a ser "valor consideravelmente elevado", porque para o reformado aquele montante era um "valor consideravelmente elevado". Forma espúria e estranha de determinação do conteúdo conceitual. Modo de operar interpretativamente em que a situação patrimonial da vítima é que determinava o conteúdo típico. Clara violação, todavia, do princípio da tipicidade.

Esquecendo-se que aquela mesma lógica — violadora da máxima: uma lei penal certa e precisa - levaria a que um furto, p. ex., de quinze ou vinte mil euros, a um multimilionário não poderia ser considerado como qualificado, porque, para aquele (vítima), por certo que o montante atrás descrito, em relação ao seu património global, não constituiria uma soma que pudesse ser sopesada como "valor consideravelmente elevado". A ideia nobre de fazer entrar a situação social da vítima (quando pobre) como elemento de determinação do elemento valor, transformava-se rapidamente em uma lâmina de dois gumes. O que mostra, também por esta óptica, a intransponível barreira que o princípio da tipicidade deve assumir para uma justa aplicação do direito penal.

Por outro lado, como se sabe, o legislador, na revisão de 1995, decidiu procurar outros caminhos para a resolução da problemática em estudo. Diga-se, de modo a clarificar, sem sofismas, as coisas, que o nosso ordenamento jurídico-penal já antes daquela data introduzira, em uma lei do direito penal secundário ${ }^{10}$, o modelo que haveria de vingar com aquela revisão do CP. Logo nessa altura, mesmo em instâncias internacionais da doutrina penal, suscitáramos algumas dúvidas quanto à bondade constitucional do modelo ali adoptado $^{11}$. De qualquer modo, para se dizer tudo, alguma doutrina continua a ignorar ou a não querer ver o problema, o que mostra também aqui a passividade do pensamento crítico dentro da cultura jurídica portuguesa. Este, por conseguinte, o estado em que, de um ponto de vista doutrinal, a questão se encontra ${ }^{12}$.

10 Então Lei n. ${ }^{\circ}$ 109/91, de 17 de Agosto, a chamada "lei da criminalidade informática", revogada pela Lei n. ${ }^{\circ}$ 109/2009, de 15 de Setembro, a chamada "lei do cibercrime".

11 Faria Costa, José de, «Les crimes informatiques et d'autres crimes dans le domaine de la technologie informatique en Portugal», Revue Internationale de Droit Pénal 64 (1993), p. 517 s., n. 42.

12 Também a propósito do que até agora se disse neste item III remete-se para o que outrora redigimos no Comentário Conimbricense do Código Penal (cit.), artigo 202. ${ }^{\circ}, \$ \$ 21-26$. 
Devido à gravidade e densidade axiológicas que acompanham a produção legislativa atinente ao direito penal, entendeu-se, sobretudo a partir do Iluminismo, que toda e qualquer construção da norma incriminadora seria da competência do parlamento. Os parlamentos têm, assim, nesta matéria uma específica e própria competência. Que pode ir de um absoluto (competência reservada absoluta) até formas mais elásticas que permitem que a Assembleia da República conceda leis de autorização legislativa, in casu, leis de autorização legislativa criminal, como sucede entre nós ${ }^{13}$.

Não se ignora que o avanço tecnológico - em tantas e variadas frentes, que vão da biomedicina à ecologia, passando pela informática, para só nos referirmos às mais candentes - veio dizer e, de certo modo, mostrar, que o espaço de discussão e de construção de leis incriminadoras referentes a tais matérias não pode, não deve ser o fórum argumentativo do Parlamento, mas antes os gabinetes profissionais dos técnicos da juridicidade, o que levaria a que o centro de gravidade da produção legiferante daquelas normas passasse, quase que pela natureza das coisas, para o Governo, para o poder executivo. A complexidade dos problemas, a dificuldade de correcta formulação jurídica, a ponderação reflexiva e intra-sistemática das molduras penais não se compaginariam com a discussão eminentemente política (ainda que político-criminal) que o Parlamento, por excelência, representa.

Se é verdade que a força de conservação do poder legislativo foi sofrendo a erosão derrapante que permite - não só em Portugal, como em tantos outros países - que o próprio poder executivo se assuma como entidade ou órgão de poder legiferante, o certo é que as constituições continuam a reservar para o poder legislativo a faculdade de legislar em matéria criminal. Quer isso significar a expressão da bondade de que só uma lei proferida pelo Parlamento ou por ele autorizada ${ }^{14}$ é juridicamente capaz de limitar direitos, liberdades e garantias. Nesta contemporaneidade, onde a rarefacção e a fragmentação da tradicional articulação dos poderes do Estado constitui moeda corrente é bom que seja o espaço público da vontade política democraticamente

13 Constituição da República Portuguesa, artigo $165 .^{\circ}$, n. ${ }^{\circ} 1$, alínea $c$ ).

14 A propósito dos problemas de legitimação suscitados pela delegação legislativa em matéria criminal: Cupelli, Cristiano, La legalità delegata. Crisi e attualità della riserva di legge nel diritto penale, Napoli: Edizioni Scientifiche Italiane, 2012, p. 15 s. 
representada o único lugar que possa, repete-se, limitar os direitos, as liberdades e garantias do cidadão.

A força normativa de uma lei em sentido estrito advém não tanto da construção jurídica que a possa sustentar, mas antes e sobretudo da crença de que é na Assembleia da República, de que é no debate de ideias parlamentar, de que é no jogo plural, conflitual e polimórfico onde as maiorias se formam que mais adequadamente se encontram as soluções correctas para a prossecução do propósito político-criminal que a norma vai encabeçar e, simultaneamente, se acredita que será também aí que mais bem defendidos ficarão os direitos, as liberdades e as garantias ${ }^{15}$.

O que há que salientar é que é no parlamento que reside, de maneira indubitável, a legitimidade da actividade legiferante incriminadora. Ora, ao aceitar-se, através de um jogo de referências extra-penais governamentais ${ }^{16}$, que o elemento valor é determinado por referência à unidade de conta processual (UC), torna-se difícil não ver a fragilidade de legitimação constitucional, por violação do princípio de reserva da lei, no que toca a um dos elementos do tipo presente em alguns dos crimes contra o património.

É evidente que a tentativa de validar o actual regime definitório na ideia de que a sua legitimidade está absolutamente coberta (cumprimento do princípio da reserva de lei), porquanto o Decreto-Lei n. ${ }^{\circ} 181 / 2008$, de 28 de Agosto, globalmente considerado, na sua versão originária, é um diploma absolutamente legítimo - o que é verdade, pois estamos perante um Decreto-Lei autorizado - que instituiu o presente sistema de indexação, afigura-se-nos não só írrita e inconsequente mas, sobretudo, tendencialmente perigosa.

Írrita e de pouca consistência teórica e doutrinal, na medida em que, se a sua lógica interna tivesse qualquer laivo de validade isso implicaria que o controlo da constitucionalidade material das normas fosse menos do que um sopro de real e efectivo controlo, fosse uma ficção ou um embuste, que um

15 Reproduz-se nestes últimos parágrafos o que já foi escrito em Faria CosTa, José de / Moura, Bruno de Oliveira, «L'interpretazione nel diritto penale: un multi verso», MANNA, Adelmo (Org.), Il problema dell'interpretazione nella giustizia penale, Pisa: Pisa University Press, 2016, p. 214 s.

16 Primeiramente, como se disse, para o Decreto-lei n. ${ }^{\circ} 212 / 89$, de 30 de Junho e, posteriormente, para o Decreto-Lei n. ${ }^{\circ} 34 / 2008$, de 26 de Fevereiro, com as vicissitudes já mencionadas relativas à suspensão, por via directa ou indirecta, da actualização automática da UC (veja-se nota 3). 
olhar mais atento e preciso não pode deixar de afastar e de problematizar quanto ao sentido e alcance da lei habilitante ${ }^{17}$.

Tendencialmente perigosa porque isso não representa menos do que uma insinuação cujo sentido fundamental se poderia encaminhar para a ideia de que é na lei extra-penal governamental e na correspondente regulamentação ministerial que se podem e devem encontrar as definições dos conteúdos dos elementos típicos dos crimes que se definem na Parte Especial do CP. Pensar assim, fácil é de ver, mais não é que querer destruir um dos pilares de um direito penal liberal.

De resto, ainda que os pilares do regime de indexação estejam ali definidos, o certo é que o actual teor do transcrito artigo $22 .^{\circ}$ do Decreto-Lei $n .^{\circ}$ 34/2008, de 26 de Fevereiro, na redação dada pelo Decreto-Lei n. ${ }^{\circ}$ 181/2008, de 28 de Agosto, decorre de diploma governamental para o qual não houve qualquer autorização parlamentar, emitido ao abrigo da alínea a) do n. ${ }^{\circ} 1$ do artigo 198. ${ }^{\circ}$ da CRP, onde se disciplina competência legislativa do Governo, em matérias não reservadas à Assembleia da República.

Uma derradeira reflexão crítica ainda a este propósito. O critério anteriormente vigente ${ }^{18}$ tinha o grande inconveniente de ligar a determinação do montante ao "momento da condenação", uma orientação que era dificilmente compatível com a ideia de que os crimes se têm sempre de ver e valorar no momento da prática dos factos. A actual orientação legal, embora evite aquela impropriedade, nada agrega em termos de previsibilidade e determinabilidade da matéria da proibição ou da qualificação a ser previamente conhecida pelos destinatários da norma.

Pois para a exacta compreensão da caracterização jurídica de sua conduta o cidadão deve ainda saber de antemão que, nos termos do art. $5 .^{\circ}$, n. $^{\circ} 2$, do Decreto-Lei n. ${ }^{\circ}$ 34/2008, de 26 de Fevereiro, "[a] UC é actualizada anual e automaticamente de acordo com o indexante dos apoios sociais (IAS), devendo atender-se, para o efeito, ao valor de UC respeitante ao ano anterior" e "o valor correspondente à UC para cada processo, tal como definido no n. ${ }^{\circ} 2$ do artigo $1 .^{\circ}$, fixa-se no momento em que o mesmo se inicia, independentemente do momento em que a taxa deva ser paga”.

17 Neste caso foi a Lei n. ${ }^{\circ}$ 26/2007, de 23 de Julho.

18 Então estabelecido no revogado art. $5 .^{\circ}$ do Decreto-lei n. ${ }^{\circ}$ 212/89, de 30 de Junho. 
Ora, tudo o que se acabou de ajuizar mais reforça, também por aqui, a nossa sustentada convicção de que se está perante um modelo dos escalões, se bem que indexado ao conteúdo definitório que leis extra-penais governamentais e a correspondente regulamentação ministerial determinam. Ou seja: nem é um verdadeiro modelo dos escalóes, nem um puro modelo normativo. É, por conseguinte, um modelo híbrido que comporta fragilidades de legitimação constitucional mais do que suficientes para que a atenção crítica da doutrina e da jurisprudência se façam sentir ${ }^{19}$.

De qualquer modo, aqui tão pouco se propõe o retorno ao antigo modelo de escalóes consagrado pelo legislador parlamentar ${ }^{20}$, atenta a constitucional reserva de lei da Assembleia da República, ainda que a favor deste resgate possa falar, de algum modo, a simples constatação de que, ao menos na economia portuguesa pós-integração na zona euro (moeda comum) e apesar das recentes crises financeiras, os índices de inflação não oscilam com a imprevisibilidade, a rapidez e a intensidade de outrora.

Pois ainda que isso corrigisse o défice de legitimação formal acima indicado, não parece que o caminho da inflexível cristalização de valores garanta a pretendida aproximação entre alcance da proteção penal do património e o concreto significado que este bem jurídico assume no seio comunitário. Embora o recurso a limiares quantitativos não seja estranho ao direito penal, tudo se torna mais complicado ali onde o que se pretende é assegurar que a dimensão jurídico-criminal da ofensa ao património possa ser apreciada em conformidade com a dimensão socioeconómica do bem jurídico.

É sabido que outros sistemas legais simplesmente prescindem de qualquer consideração do valor da coisa subtraída para efeitos de construção legal de

19 Nestes últimos parágrafos novamente se segue a argumentação por nós vertida, ao abrigo dos diplomas governamentais anteriores, no Comentário Conimbricense do Código Penal. Parte Especial (cit.), artigo $202 .^{\circ}, \$ \$ 27-29$.

20 Tal como hoje faz o $\$ 128$ I (n. ${ }^{\circ}$ 5) e II do Código Penal austríaco, onde se prevê pena de prisão de até 3 anos quando o valor da coisa exceder os 5.000 euros e pena de prisão de 1 até 10 anos quando o valor da coisa exceder os 300.000 euros. 
um tipo de furto qualificado ou que só reconhecem uma atenuação da pena quando, entre outros pressupostos, o furto tem um objeto de escasso valor, sem definição legal específica deste limiar, como é o caso do direito italiano (n. 2 do artigo $\left.626 \mathrm{do} \mathrm{CP}^{21}\right)^{22}$. Bem vistas as coisas, ambos os modelos implicam admitir que o problema que as cláusulas de valor pretendem resolver é, no fundo, um problema de determinação judicial da sanção.

Cumpre reconhecer que este entendimento não é afectado por nenhuma objecção de princípio. Com efeito, se argumentarmos no plano da teoria das normas e procurarmos pela autêntica regra de ilicitude do crime de furto, será fácil perceber que o comando dirigido ao cidadão não é propriamente a proibição de subtrair — com ânimo de apropriação — uma coisa alheia móvel com um valor abaixo ou acima de $X$, mas sim a proibição de subtrair uma coisa alheia móvel de qualquer valor, desde que economicamente relevante $^{23}$. Coisa substancialmente diversa, ainda que formalmente se indicie o contrário, é a necessidade - não apenas político-criminalmente fundada, mas também apoiada da pretensão de realização da justiça do caso — de fazer com que a uma considerável diferença de valor económico entre os objetos de acção corresponda uma diferença de valoração jurídica no horizonte do sancionamento.

Também isso depõe a favor daquela que, aos nossos olhos, seria a solução de técnica legislativa mais adequada: a manutenção das fórmulas legais "de valor elevado" e "de valor consideravelmente elevado", mas agora compreendidas não como mecanismos de reenvio para normações extrapenais governamentais, mas sim como genuínas cláusulas gerais (ou conceitos relativamente indeterminados) que requerem, em cada específica situação concreta,

21 Desde que cometido para suprir uma necessidade séria e urgente.

22 Semelhante nos efeitos é a solução do código penal alemão ( $\$ \$ 243$ II e 248a), onde o valor diminuto é negativamente considerado como um factor relevante para o afastamento do tipo de furto qualificado e a sujeição a um regime de perseguibilidade mais favorável (dependente de queixa particular, em regra). Cf. Sснмidt, Jens, Comentários feitos em Matt, Holger / Renzikowski, Joachim (Hrsg.), Strafgesetzbuch Kommentar, München: Vahlen, 2013, \$243 nm. 19 e $\$ 248$ a nm. 3, com indicações sobre a divergência das opinióes quanto ao limiar de escassez. Algo parecido ocorre no código penal suíço (n. ${ }^{\text {os }} 2$ e 3 do artigo $139 \mathrm{e} \mathrm{n}$. 1 do artigo 172ter): nos casos de diminuto valor da coisa o agente só pode ser punido com multa e apenas na sequência de queixa particular.

23 Sendo este último um elemento implícito do tipo: Faria Costa, José de, Direito Penal Especial. Contributo para a sistematização dos problemas especiais da Parte Especial, Coimbra: Coimbra Editora, 2004, p. 70 s. 
a pertinente densificação judicial. Contra tal modelo não fala, obrigatoriamente, a exigência de determinabilidade da lei incriminadora. Pois, como se sabe, esta vertente do princípio da legalidade não exclui a possibilidade de recorrer a tais cláusulas, desde que se entenda haver razões ponderosas (de ultima ratio) para tanto.

Se não vemos mal, é o que acontece no horizonte do crime de furto. Entre os inconvenientes da rigidez de um puro modelo de escalóes, definido seja pelo parlamento, seja pelo governo, e um modelo de completa irrelevância típica do valor do objecto da acção, que hipostasia unilateralmente a dimensão institucional (não-económica) do bem jurídico, a forma mais adequada para garantir que a ofensa jurídico-criminalmente relevante ao património possa ser graduada no horizonte da tipicidade é confiar ao juiz o poder para aferir e actualizar, em cada particular circunstancialismo histórico, aquilo que se deve entender por valor elevado e valor consideravelmente elevado ${ }^{24}$.

Sublinhe-se, no entanto, a traço grosso: com isso não se propõe, evidentemente e pelos motivos já assinalados, a aplicação de critérios subjectivos, orientados seja pela individualidade da vítima, seja pela individualidade do julgador. O parâmetro de decisão sempre deverá ser objectivo, tendo-se em conta aquilo que, na perspectiva da consideração do património como bem jurídico economicamente dinâmico, puder ser padronizado, em cada ciclo macroeconómico nacional, como dimensão dotada da espessura suficiente para a imputação juridicamente controlada daqueles qualificativos. Não se trata de simples e mero arbítrio, mas de alguma discricionariedade judicativa. Não maior, por certo, do que aquela que está implicada, $v$.g., na cláusula que condiciona a validade de consentimento do ofendido à observância dos bons costumes, referida no $n .^{\circ} 1$ do artigo $38 .^{\circ}$ do código penal português.

Por fim, tão-pouco caberá invocar, no sentido contrário do aqui proposto, que o direito penal conhece e admite situações de reenvio da definição da matéria de proibição para determinações extra-penais e infra-legais (governamentais, administrativas) assim se caracterizando a figura das chamadas normas penais em branco (em sentido estrito). Afinal, este é um fenómeno — ou se assim se preferir, sem exagero, uma tendência — do já mencionado direito penal secundário, onde há uma maior inclinação para se reconhecer

24 Veja-se, por exemplo, o artigo 139, n. ${ }^{\text {ss }} 2$ e 3, do Código Penal suíço. 
alguma relativização das exigências do princípio da legalidade criminal, na vertente da determinabilidade da conduta típica. O que, naturalmente, não pode ser sustentado para uma área tão nuclear do direito penal clássico, como o direito penal patrimonial. Na verdade, assim é. Pensar de modo contrário, é possível, tem sido possível, por certo, mas então tem que se admitir que o esforço de categorização que a dogmática penal leva a cabo, enquanto manifestação de tutela dos valores de segurança e de certeza jurídicas, de pouco ou nada servem. E isso não o admitimos. Precisamente porque prezamos, sobremaneira, os valores da segurança e da certeza jurídicas. 
